\title{
In situ phase transformation of Laves phase from Chi-phase in Mo-containing $\mathrm{Fe}-\mathrm{Cr}-\mathrm{Ni}$ alloys
}

L. Tan*, Y. Yang

Oak Ridge National Laboratory, Oak Ridge, TN 37831, USA

* Corresponding author: One Bethel Valley Road, P.O. Box 2008, MS-6136, Oak Ridge, TN

37831; Phone: +1-865-574-4628; E-mail: tanl@ornl.gov (L. Tan)

\begin{abstract}
An in situ phase transformation of the Chi $(\chi)$ phase to the Laves phase was observed in a FeCr-Ni-Mo model alloy. The morphology, composition, and crystal structure of the $\chi$ and Laves phases, and their orientation relationship with the matrix austenite phase were investigated. The resulted Laves phase has larger lattice mismatch with the matrix phase than the $\chi$ phase, leading to the increase of local strain fields and the formation of dislocations. This finding is helpful to understand the precipitation behavior of the intermetallic phases in the Mo-containing austenitic stainless steels.
\end{abstract}

Keywords: Mo-containing stainless steels; TEM; Microstructure; Phase transformation

\section{Introduction}

Molybdenum (Mo)-containing austenitic stainless steels such as type 316 and its variants have been extensively used as structural materials in steam generating plants and nuclear reactors because of their good mechanical properties, excellent corrosion resistance, and fabricability [1]. However, these materials suffer embrittlement during long-term thermal aging at temperatures below $920^{\circ} \mathrm{C}$ due to the precipitation of intermetallic phases such as Chi $(\chi)$, Laves, and Sigma $(\sigma)$ $[2,3,4]$. While the $\sigma$ phase has been studied in depth recently [5,6], the $\chi$ and Laves phases are less investigated.

The $\chi$ phase was identified as being $\mathrm{Cr}_{6} \mathrm{Fe}_{18} \mathrm{Mo}_{5}$ in the Cr-Fe-Mo ternary with a bodycentered-cubic (bcc, I-43 m space group) structure and a lattice parameter of $0.892 \mathrm{~nm}$ [7]. The 
Laves phase is primarily in the form $\mathrm{Fe}_{2} \mathrm{Mo}$ with a hexagonal structure ( $\mathrm{P}_{3} / \mathrm{mmc}$ space group) and lattice parameters of $\mathrm{a}=0.473 \mathrm{~nm}$ and $\mathrm{c}=0.772 \mathrm{~nm}$ [2]. The $\chi$ and Laves phases both contain noticeable amounts of Mo. The Mo content increases from $\sim 17$ at $\%$ in the $\chi$ phase up to $\sim 33$ at $\%$ in the Laves phase, according to their nominal compositions. Although limited study on the precipitation behavior of either the $\chi$ or the Laves phase in an austenitic $(\gamma)$ matrix has been reported in literature [8,9], the in situ phase transformation between the $\chi$ and Laves phases was observed for the first time in this work.

\section{Experimental methods}

To study the phase transformation between the $\chi$ and Laves phases, a high-Mo-content model alloy was designed to have a composition of $\mathrm{Fe}-13.2 \mathrm{Cr}-14.2 \mathrm{Mo}-12.9 \mathrm{Ni}$ in weight percentage (wt \%), using computational thermodynamics with an optimized thermodynamic database [10]. The calculated phase amount in the alloy as a function of temperature is shown in Fig. 1. The amounts of the $\chi$ and Laves phases at $850^{\circ} \mathrm{C}$ were great enough to facilitate experimental characterization. The alloy was fabricated using arc melting in an argon atmosphere. The melted button was flipped and remelted ten times to ensure good homogenization before drop-cast into a cylindrical copper mold. The total weight loss of the alloy was less than $0.1 \%$. Samples were then cut from the drop-cast rod, sealed into evacuated quartz capsules and annealed at $850^{\circ} \mathrm{C}$ for $168 \mathrm{~h}$ (7 days), followed by water quenching to obtain coexisting $\chi$ and Laves phases in the austenitic matrix.

$\mathrm{X}$-ray diffraction (XRD) was conducted on the annealed sample using Mo-K $\alpha$ radiation $(\lambda=$ $0.709319 \AA$ A ) and the results were analyzed using CrystalMaker and CrystalDiffract software [11]. The detailed microstructures of the annealed samples were characterized using transmission electron microscopy (TEM) with a Philips CM200 field emission gun microscope at $200 \mathrm{kV}$. The 
phase composition was measured by energy dispersive $\mathrm{x}$-ray spectroscopy. TEM discs $3 \mathrm{~mm}$ in diameter were mechanically polished to $\sim 0.1 \mathrm{~mm}$ and then electro-polished to perforation using a Struers Tenupol polishing unit with a methyl sulfuric $(7: 1)$ solution at $\sim 140 \mathrm{~mA}$ and $-12^{\circ} \mathrm{C}$.

\section{Results and Discussion}

The XRD results, shown in Fig. 2, illustrate the presence of a decent amount of $\chi$ phase with relatively high peak intensities and a small amount of Laves phase, in addition to the austenitic matrix; these results are qualitatively consistent with the calculated amount of individual phases in Fig. 1. The lattice parameters of the three phases were analyzed being $\mathrm{a}_{y}=0.359 \mathrm{~nm}, \mathrm{a}_{\chi}=$ $0.891 \mathrm{~nm}, \mathrm{a}_{\text {Laves }}=0.4735 \mathrm{~nm}$, and $\mathrm{c}_{\text {Laves }}=0.7655 \mathrm{~nm}$.

A typical bright field (BF) TEM image of the annealed sample in a (220) two-beam condition near the [110] zone axis of the matrix austenite phase is shown in Fig. 3a. It exhibits coarse and fine particles precipitated in the matrix. The selected-area-diffraction pattern (SADP) is shown as an inset. The coarse particles were identified as the $\chi$ phase with a composition of approximately $\mathrm{Cr}_{21} \mathrm{Fe}_{58} \mathrm{Mo}_{16} \mathrm{Ni}_{5}$. Some fine particles were also identified as the $\chi$ phase. Figure $3 \mathrm{~b}$ shows an example of a fine $\chi$-phase particle imaged in dark-field (DF) using the (110) reflection near the [110] zone axis of the particle. The particle contains many cells $\sim 100 \mathrm{~nm}$ in size, which are outlined by dislocations, as shown in Fig. 3c taken from one of the cell boundaries in Fig. 3b. The lattice fringe orientation of the particle was not altered by the dislocation boundary of the cells. The lattice fringes correspond to the (110) planes with a measured interspacing of 0.630 $\mathrm{nm}$, corresponding to a lattice parameter of $0.891 \mathrm{~nm}$ for the $\chi$-phase particle, which is consistent with the XRD result.

In addition to the $\chi$ phase, the Laves phase was also identified in the annealed samples. In contrast to the single-phase particles of the $\chi$ phase, the Laves phase was found to coexist with 
the $\chi$ phase. Figure $4 \mathrm{a}$ in $\mathrm{BF}$, which was taken under the same condition as Fig. 3a, exhibits an example of such a dual-phase particle, in which the grey regime (labeled "b") is identified as Laves phase and the adjacent dark regime (labeled "c") as $\chi$ phase. High-resolution BF images of the two phases are shown in Fig. 4b and 4c, respectively, with their corresponding Fast Fourier Transform (FFT) patterns as insets. Based on thermodynamic calculation in Fig. 1, the decomposition of the $\chi$ phase is through the eutectoid reaction of $\chi \rightarrow \gamma+$ Laves. The image in Fig. 4a suggests this reaction begins at the interphase boundary between the $\chi$ phase and the austenite phase, and then the $\chi$ phase is consumed by forming the Laves phase and the new austenite phase. According to the Moiré fringes of the Laves particle (Fig. 4b) with a measured spacing $(D)$ of $0.865 \mathrm{~nm}$, and its relationship with the interplanar spacing of the matrix $\left(d_{1}=d_{(220)}\right)$ and Laves phase $\left(d_{2}=d_{(211)}=0.1519 \mathrm{~nm}\right)$ as $D=d_{1} d_{2} / d_{1}-d_{2} \mid$ [12], the matrix $d_{1}=d_{(220)}$ can be calculated as $0.1292 \mathrm{~nm}$, corresponding to $\mathrm{a}_{\gamma}=0.3655 \mathrm{~nm}$. Compared with the XRD result of $\mathrm{a}_{\gamma}=0.359 \mathrm{~nm}$, the presence of the Laves particle increases locally the lattice parameter of the matrix by $\sim 1.81 \%$. Similarly, $\sim 1.59 \%$ increase in lattice parameter was calculated from Fig. 4c for the matrix adjacent to the $\chi$ phase. The slightly smaller increase in the lattice parameter of the local matrix close to the $\chi$ phase compared with the matrix close to the Laves phase indicates that the phase transformation of the $\chi$ phase to the Laves phase increased the local strain field, which may increase embrittlement tendency of this type of alloys. The large strain field between the Laves phase and the matrix resulted in the discontinuity of the lattice fringes of the Laves particle in Fig. 4b, leading to some superposition strong reflections in Fig. 4d, taken from the white dashed circle in Fig. 4a.

Figure $4 \mathrm{~d}$ was processed using the logarithm mathematical function in ImageJ [13] to maximize the visibility of the dim reflections from the particle. Its analytical result is shown in 
Fig. 4e, indicating the enclosure of three phases of $\chi$, Laves, and the matrix in the zone axis near

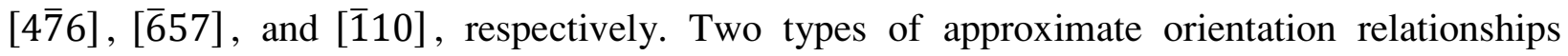
between the phases, marked with black and grey arrows in Fig. 4e, are revealed as

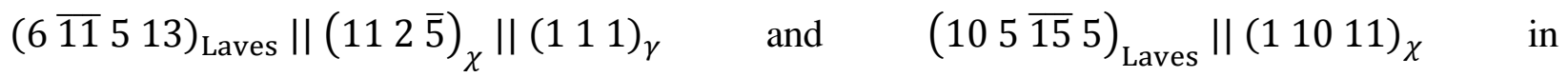
$\left[\begin{array}{lll}\overline{6} & 5 & 1\end{array}\right]_{\text {Laves }}\left\|\left[\begin{array}{lll}4 & \overline{7} & 6\end{array}\right]_{\chi}\right\|\left[\begin{array}{lll}\overline{1} & 1 & 0\end{array}\right]_{\gamma}$. Considering the local strain fields induced by the in situ $\chi$ Laves phase transformation, the orientation relationships between the phases can be approximated by $(0 \overline{1} 11)_{\text {Laves }}\left\|(10 \overline{1})_{\chi}\right\|(111)_{\gamma}$ and $(21 \overline{3} 1)_{\text {Laves }} \|(011)_{\chi} \quad$ in $[\overline{1} 101]_{\text {Laves }}\left\|[1 \overline{1} 1]_{\chi}\right\|[\overline{1} 10]_{\gamma}$. The orientation relationship between the $\chi$ phase and the austenitic matrix follows the Kurdjumov-Sachs relationship, consistent with a literature report [8]. The orientation relationship between the transformed Laves phase and the austenitic matrix is different from the observed $(10 \overline{1} 3)_{\mathrm{Fe}_{2} \mathrm{Mo}}\left\|(111)_{\gamma}, \quad[\overline{1} 2 \overline{1} 0]_{\mathrm{Fe}_{2} \mathrm{Mo}}\right\|[\overline{1} 2 \overline{1}]_{\gamma}$ and $(0001)_{\mathrm{Fe}_{2} \mathrm{Nb}}\left\|(111)_{\gamma},[10 \overline{1} 0]_{\mathrm{Fe}_{2} \mathrm{Nb}}\right\|[\overline{1} 10]_{\gamma}[14]$.

\section{Conclusion}

An in situ phase transformation of the Chi $(\chi)$ phase to the Laves phase was observed in a FeCr-Ni-Mo model alloy using TEM primarily. In contrast to the coarse and fine single-phase particles of the $\chi$ phase, the Laves phase was always found to coexist with some fine $\chi$ phase particles. The Laves phase has larger lattice mismatch with the matrix austenite phase than the $\chi$ phase, leading to the increase of local strain fields and the formation of dislocations.

\section{Acknowledgement}

This research was supported by the US Department of Energy (DOE), Office of Nuclear Energy, Light Water Reactor (LWR) program and Nuclear Engineering Enabling Technology (NEET) Advanced Reactor Material Program Cross-Cut activity, under contract DE-AC0500OR22725 with UT-Battelle, LLC. 


\section{References}

[1] Zinkle SJ, Busby JT. Structural materials for fission and fusion energy. Mater Today 2009;12:12-19.

[2] Weiss B, Stickler R. Phase instabilities during high temperature exposure of 316 austenitic stainless steel. Metall Trans 1972;3:851-866.

[3] Morris D. The influence of sigma phase on creep ductility in type 316 stainless steel. Scripta Metall 1979;13:1195-1196.

[4] Sourmail T. Precipitation in creep resistant austenitic stainless steels. Mater Sci Tech 2001;17:1-14.

[5] Schwind M, Källqvist J, Nilsson JO, Ågren J, Andrén HO. $\sigma$-phase precipitation in stabilized austenitic stainless steels. Acta Mater 2000;48:2473-2481.

[6] Perron A, Toffolon-Masclet C, Ledoux X, Buy F, Guilbert T, Urvoy S, Bosonnet S, Marini B, Cortial F, Texier G, Harder C, Vignal V, Petit Ph, Farré J, Suzon E. Understanding sigma-phase precipitation in a stabilized austenitic stainless steel $(316 \mathrm{Nb})$ through complementary CALPHAD-based and experimental investigations. Acta Mater 2014;79:1629.

[7] Kasper JS. The ordering of atoms in the chi-phase of the iron-chromium-molybdenum system. Acta Metall 1954;2:456-461.

[8] Lee TH, Kim SJ. Phase identification in an isothermally aged austenitic $22 \mathrm{Cr}-21 \mathrm{Ni}-6 \mathrm{Mo}-\mathrm{N}$ stainless steel. Scripta Mater 1998;39:951-956.

[9] Denham AW, Silcock JM. Precipitation of $\mathrm{Fe}_{2} \mathrm{Nb}$ in a 16 wt $\% \mathrm{Ni} 16$ wt $\% \mathrm{Cr}$ steel, and the effect of Mn and Si additions. J Iron Steel Inst 1969;207:585-592.

[10] Yang Y, Tan L, Busby JT. Thermal stability of precipitate phases in Fe-rich Fe-Cr-Ni-Mo alloys, submitted to Metall. Trans. A 2014.

[11] http://www.crystalmaker.com

[12] Fultz B, Howe JM. Transmission electron microscopy and diffractometry of materials. $3^{\text {rd }}$ ed. Heidelberg: Springer; 2008.

[13] ImageJ - Image Processing and Analysis in Java (http://imagej.nih.gov/ij/).

[14]Marshall P. Austenitic stainless steels: microstructure and mechanical properties. New York: Elsevier Applied Science Publishers, Ltd.; 1984. 


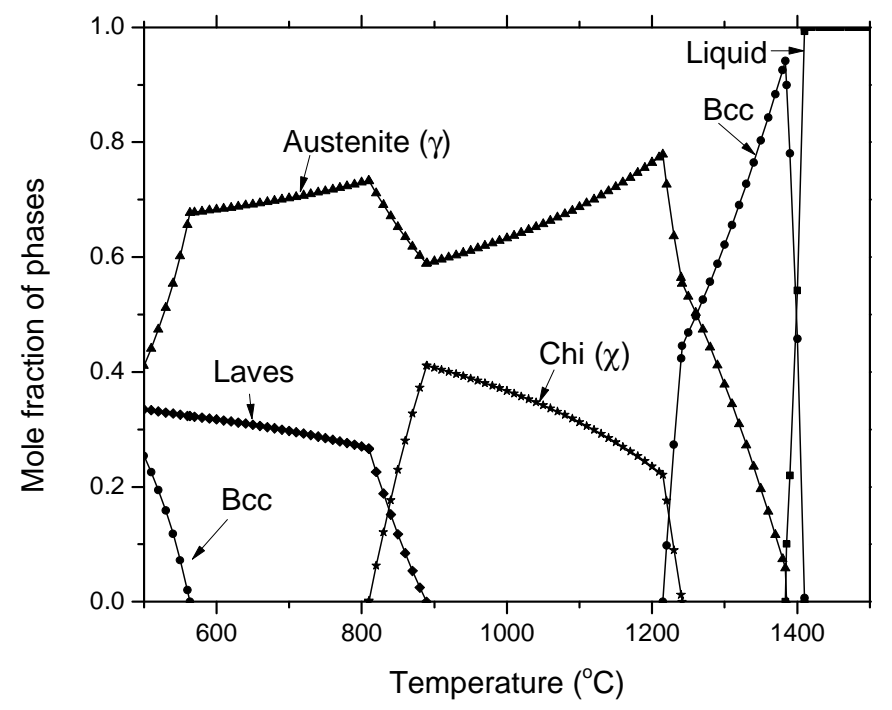

Fig. 1. Calculated temperature-dependent phase mole fraction in alloy Fe-13.2Cr-14.2Mo-12.9Ni.

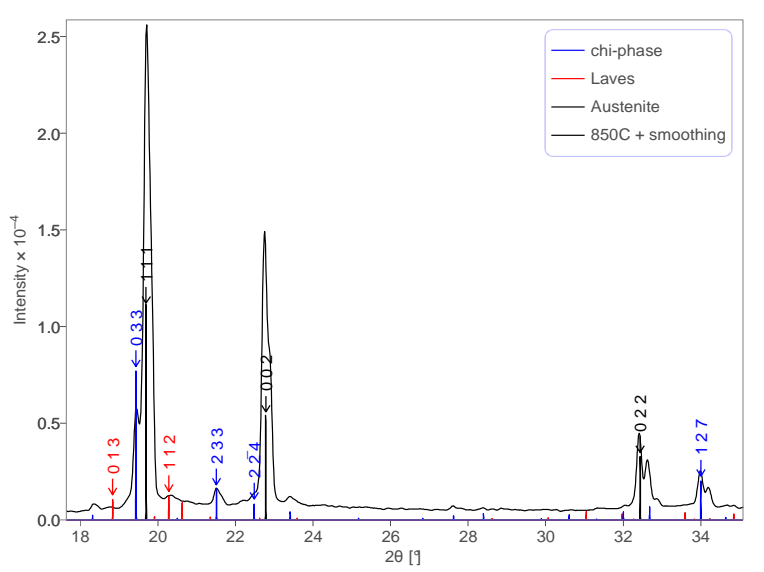

Fig. 2. X-ray diffraction pattern of the $850^{\circ} \mathrm{C}$-annealed sample, together with the simulated patterns (Mo-K $\alpha)$ of the Chi, Laves, and austenite phases for comparison. 


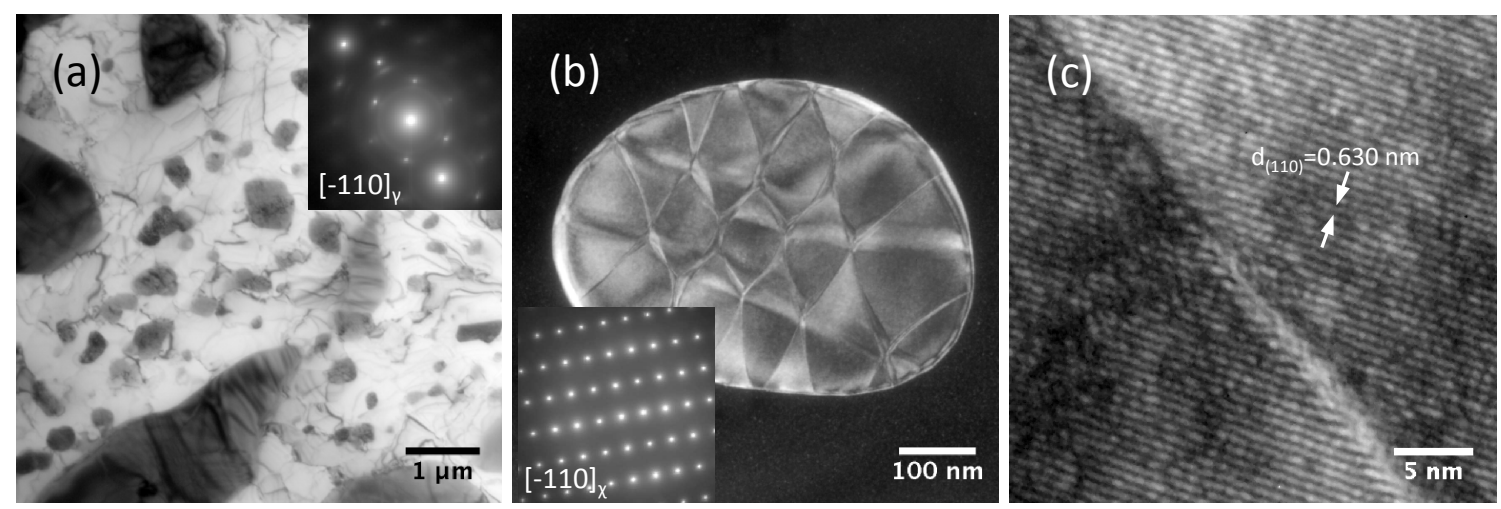

Fig. 3. Microstructure of the $850^{\circ} \mathrm{C}$-annealed sample: (a) $\mathrm{BF}$ image showing both coarse and fine precipitates, (b and c) DF and BF images showing a fine $\chi$-phase particle.
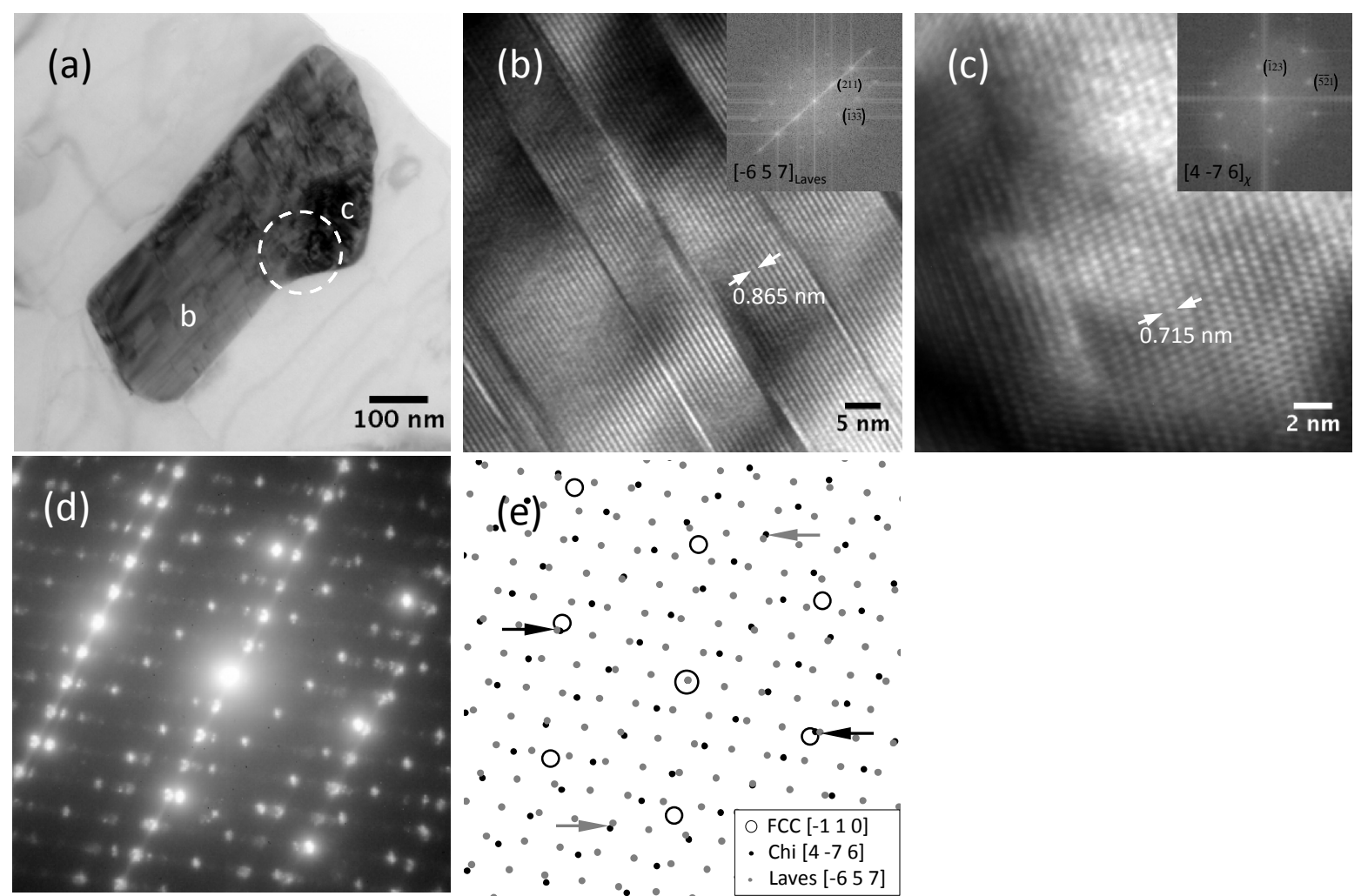

Fig. 4. (a) BF image of a Laves- $\chi$ particle in the $850^{\circ} \mathrm{C}$-annealed sample, together with its highresolution BF images of (b) Laves phase, (c) $\chi$-phase, (d) SADP, and (e) analytical diffraction pattern. 